\title{
The Canadian Perinatal Network: A National Network Focused on Threatened Preterm Birth at 22 to 28 Weeks' Gestation
}

Laura A. Magee, MD, FRCPC, ${ }^{1-4}$ Peter von Dadelszen, MB ChB, DPhil, FRCSC, ${ }^{2-4}$

Victoria M. Allen, MD, FRCSC, ${ }^{5}$ John M. Ansermino, MB ChB, PhD, FRCPC, ${ }^{6}$

François Audibert, MD, FRCSC, ${ }^{7}$ Jon Barrett, MD, FRCSC, ${ }^{8}$ Rollin Brant, PhD, ${ }^{9}$

Emmanuel Bujold, MD, FRCSC, ${ }^{10}$ Joan M.G. Crane, MD, FRCSC, ${ }^{11}$ Nestor Demianczuk, MD, FRCSC, ${ }^{12}$ K.S. Joseph, MD, PhD, ${ }^{2-4}$ Shoo K. Lee, MB BS, PhD, FRCPC, ${ }^{13}$ Bruno Piedboeuf, MD, PhD, FRCPC, ${ }^{14}$ Graeme Smith, MD, FRCSC,,$^{15}$ Anne Synnes, MD, FRCPC, ${ }^{16}$ Mark Walker, MD, FRCSC, ${ }^{17}$

Wendy Whittle, MD, PhD, FRCSC, ${ }^{18}$ Stephen Wood, MD, FRCSC, ${ }^{19}$ Tang Lee, MSc, ${ }^{2}$ Jing Li, MCS, ${ }^{2}$ Beth Payne, BSc, ${ }^{12}$ Robert M. Liston, MB ChB, FRCSC ${ }^{2,4}$; for the Canadian Perinatal Network Collaborative Group (Appendix 2)

1Department of Medicine, University of British Columbia, Vancouver BC

${ }^{2}$ Department of Obstetrics and Gynaecology, University of British Columbia, Vancouver BC

${ }^{3}$ School of Population and Public Health, University of British Columbia, Vancouver BC

${ }^{4}$ Child and Family Research Institute, University of British Columbia, Vancouver BC

${ }^{5}$ Department of Obstetrics and Gynaecology, Dalhousie University, Halifax NS

${ }^{6}$ Department of Anesthesia, University of British Columbia, Vancouver BC

${ }^{7}$ Department of Obstetrics and Gynecology, Université de Montréal, Montreal QC

${ }^{8}$ Department of Obstetrics and Gynaecology, Sunnybrook Health Sciences Centre, Toronto ON

${ }^{9}$ Department of Biostatistics, University of British Columbia, Vancouver BC

${ }^{10}$ Department of Obstetrics and Gynecology, Université Laval, Quebec QC

${ }^{11}$ Department of Obstetrics and Gynecology, Memorial University of Newfoundland, St. John's NL

${ }^{12}$ Department of Obstetrics and Gynecology, University of Alberta, Edmonton AB

${ }^{13}$ Department of Paediatrics University of Toronto, Toronto ON

${ }^{14}$ Department of Neonatology, Université Laval, Quebec QC

${ }^{15}$ Department of Obstetrics and Gynaecology, Queen's University, Kingston ON

${ }^{16}$ Department of Pediatrics, University of British Columbia, Vancouver BC

${ }^{17}$ Department of Obstetrics and Gynecology, University of Ottawa, Ottawa ON

${ }^{18}$ Department of Obstetrics and Gynaecology, University of Toronto, Toronto ON

${ }^{19}$ Department of Obstetrics and Gynaecology, University of Calgary, Calgary ON

\section{Abstract}

Objective: The Canadian Perinatal Network (CPN) maintains an ongoing national database focused on threatened very preterm birth. The objective of the network is to facilitate between-hospital comparisons and other research that will lead to reductions in the burden of illness associated with very preterm birth.

Methods: Women were included in the database if they were admitted to a participating tertiary perinatal unit at $22+0$ to $28+6$ weeks' gestation with one or more conditions most commonly responsible for very preterm birth, including spontaneous preterm labour with contractions, incompetent cervix, prolapsing membranes, preterm prelabour rupture of membranes, gestational hypertension, intrauterine growth restriction, or antepartum hemorrhage. Data were collected by review of maternal and infant charts, entered directly into standardized electronic data forms and uploaded to the CPN via a secure network.

Results: Between 2005 and 2009, the CPN enrolled 2524 women from 14 hospitals including those with preterm labour and contractions (27.4\%), short cervix without contractions (16.3\%), prolapsing membranes $(9.4 \%)$, antepartum hemorrhage $(26.1 \%)$, and preterm prelabour rupture of membranes (23.0\%). The mean gestational age at enrolment was $25.9 \pm 1.9$ weeks and the mean gestation age at delivery was $29.9 \pm 5.1$ weeks; $57.0 \%$ delivered at $<29$ weeks and $75.4 \%$ at $<34$ weeks. Complication rates were high and included serious maternal complications $(26.7 \%)$, stillbirth $(8.2 \%)$, neonatal death (16.3\%), neonatal intensive care unit admission (60.7\%), and serious neonatal morbidity (35.0\%).

Conclusion: This national dataset contains detailed information about women at risk of very preterm birth. It is available to clinicians and researchers who are working with one or more 
CPN collaborators and who are interested in studies relating processes of care to maternal or perinatal outcomes.

\section{Résumé}

Objectif : Le Réseau périnatal canadien (RPC) tient une base de données nationale continue centrée sur l'accouchement très prématuré appréhendé. L'objectif du réseau est de faciliter les comparaisons interhôpitaux et la tenue d'autres recherches qui mèneront à des réductions du fardeau de la maladie associé à l'accouchement très prématuré.

Méthodes : Les femmes étaient incluses à la base de données Iorsqu'elles étaient admises dans une unité périnatale tertiaire participante entre $22+0$ et $28+6$ semaines de gestation en raison de la présence d'un ou de plusieurs des états pathologiques les plus couramment à l'origine de l'accouchement très prématuré (dont le travail préterme spontané s'accompagnant de contractions, la béance du col utérin, le prolapsus des membranes, la rupture prématurée des membranes préterme, l'hypertension gestationnelle, le retard de croissance intra-utérin ou l'hémorragie antepartum). Les données ont été recueillies au moyen de l'analyse des dossiers maternels et infantiles, saisies directement dans des formulaires de données électroniques standardisés et téléchargées dans le RPC par l'intermédiaire d'un réseau sécurisé.

Résultats : Entre 2005 et 2009, le RPC a sollicité la participation de 2524 femmes issues de 14 hôpitaux, y compris celles qui présentaient un travail préterme s'accompagnant de contractions $(27,4 \%)$, un col court sans contractions (16,3\%), un prolapsus des membranes $(9,4 \%)$, une hémorragie antepartum $(26,1 \%)$ et la rupture prématurée des membranes préterme (23,0\%). L'âge gestationnel moyen au moment de l'admission à l'étude était de 25,9 $\pm 1,9$ semaines et l'âge gestationnel moyen au moment de l'accouchement était de 29,9 $\pm 5,1$ semaines; $57,0 \%$ ont accouché à $<29$ semaines et $75,4 \%$, à < 34 semaines. Les taux de complication étaient élevés et comptaient des complications maternelles graves $(26,7 \%)$, la mortinaissance $(8,2 \%)$, le décès néonatal $(16,3 \%)$, l'admission à l'unité néonatale des soins intensifs $(60,7 \%)$ et la morbidité néonatale grave $(35,0 \%)$.

Conclusion : Cet ensemble de données nationales renferme des renseignements détaillés sur les femmes exposées à des risques de connaître un accouchement très prématuré. II est mis à la disposition des cliniciens et des chercheurs qui travaillent avec un ou plusieurs collaborateurs du RPC et qui s'intéressent aux études cherchant à établir des liens entre les processus de soins et les issues maternelles ou périnatales.

J Obstet Gynaecol Can 2011;33(2):111-120

\section{INTRODUCTION}

$\mathrm{T}$ the Canadian Perinatal Network is an initiative funded by the Canadian Institutes for Health Research that maintains a national database of information collected from a prospective cohort of women at high risk for very preterm birth (i.e., between $22+0$ and $28+6$ weeks' gestation). This ongoing initiative was designed to examine how differences

Key Words: Maternal complications, perinatal complications quality improvement, variation, preterm labour

Competing Interests: None declared.

Received on July 26, 2010

Accepted on September 13, 2010 in maternal and perinatal outcomes between tertiary perinatal units in Canada might be explained by variations in obstetric and neonatal care practices. Towards this end, the CPN collects information on adverse maternal, fetal, and neonatal outcomes, obstetric and neonatal care practices, and maternal and pregnancy characteristics among women with threatened very preterm birth.

Although maternal mortality is rare in Canada (with a maternal mortality ratio of 5.5 deaths per 100000 live births in 2002 to 2004), ${ }^{1}$ serious maternal morbidity remains a concern, especially among women with threatened very preterm birth. Maternal complications may be related to underlying disease (e.g., the 20-fold increased risk of maternal mortality/serious morbidity associated with early gestational hypertension and proteinuria), direct complications of the obstetric problem (e.g., chorioamnionitis associated with preterm prelabour rupture of membranes), or treatment (e.g., thromboembolism associated with bed rest prescribed for fetal growth restriction). ${ }^{2,3}$ To date, severe maternal morbidity associated with very preterm delivery has not been adequately studied.

One major obstacle to a pan-Canadian study of maternal and infant complications associated with threatened very preterm birth is the absence of detailed information on this condition. Although many current regional or provincial perinatal health programs collect information on perinatal issues, these databases have been designed primarily for perinatal surveillance. The programs do not cover the entire country, and definitions have not been harmonized. ${ }^{4}$ Most importantly, there is insufficient obstetric practice information for determining what aspects of care result in the best outcomes for mothers and babies.

We describe here the baseline characteristics and outcomes for the first 2524 women enrolled in the CPN. Our objective is to generate interest in this database, which is available to clinicians and investigators who work with a CPN collaborator and who are interested in conditionspecific analyses of the relationship between processes of care and maternal or perinatal outcomes.

\section{METHODS}

The CPN was initially funded by the Canadian Institutes for Health Research in March 2005, to focus on the optimal management of threatened very preterm birth at $22+0$ to $28+6$ weeks' gestation. Data collection began in August 2005, and by July 31, 2009, the CPN database contained data from 14 of Canada's 23 tertiary perinatal units. Three additional sites are poised to start data collection. All sites 
completed a questionnaire about resources and practices at their centre. The Research Ethics Committee at each participating centre reviewed and approved the CPN as a quality assurance project that did not require individual informed consent. Experience with this process has been detailed elsewhere. ${ }^{5}$

Women had data from their pregnancy submitted to the CPN if they were admitted to a participating tertiary perinatal unit at $22+0$ to $28+6$ weeks' gestation with one or more of the following "indicator" conditions most commonly responsible for very preterm birth: spontaneous PTL with contractions, incompetent cervix, prolapsing membranes, PPROM, gestational hypertension, IUGR, or antepartum hemorrhage. All hospitals used standard definitions for the indicator conditions and maternal and perinatal outcomes identified (Appendix 1). If a woman contributed data from more than one pregnancy to the CPN, we included only the data from the first pregnancy in this analysis. Women seen in the triage area or obstetrical day unit of a participating hospital and subsequently discharged were not enrolled in the CPN. For women admitted to hospital but subsequently discharged before delivery, all subsequent re-admissions were recorded in the CPN, up to and including delivery. If the patient was transferred to another facility, the woman and her baby or babies were considered lost to follow-up if delivery information could not be obtained.

Each participating centre identified its own data abstractor. The abstractor received a CPN Working Protocol and detailed CPN Database Manual (v2.0). A two-day training seminar was held in Vancouver, BC in April 2006, prior to data collection. A day-long site visit was made to each active centre by the central CPN Coordinator, who also offered ongoing support for questions that arose after training and site visits. Quarterly newsletters addressed changes and frequently asked questions.

Data abstractors identified potentially eligible women either from the delivery suite and antenatal ward logbooks

\section{ABBREVIATIONS \\ $\mathrm{APH}$ antepartum hemorrhage \\ CNN Canadian Neonatal Network \\ CPN Canadian Perinatal Network \\ IQR interquartile range \\ IUGR intrauterine fetal growth restriction \\ PPROM preterm prelabour rupture of membranes}

PTL preterm labour
(9 centres) or from Canadian Institute for Health Information coded data searches using the gestational age at admission (5 centres). Regardless, the data abstractor reviewed the maternal chart and verified whether the patient met CPN inclusion criteria. Data were collected by review of the maternal and infant records, from hospital admission at eligibility until final discharge from hospital after delivery (and if relevant, including subsequent postpartum re-admissions). Maternal information collected included maternal characteristics, obstetrical history, past medical history, risk factors and screening in the current pregnancy, details of the hospital admission, maternal (and fetal) surveillance, maternal interventions including pharmacotherapy, maternal outcomes, and delivery data. Data related to neonatal outcomes were obtained from two sources. For babies admitted to a neonatal intensive care unit, probabilistic linkage was used to obtain data from the Canadian Neonatal Network, a sister network of CPN in the Maternal-Infant Care Network (MiCare). For babies admitted to NICU for $<24$ hours, or not admitted to NICU, data were obtained directly from the neonatal hospital record. When a woman did not deliver at the CPN site at which she was first enrolled, every effort was made to obtain delivery and neonatal information from available sources.

Data were entered directly into the standardized electronic data collection forms and uploaded to CPN from each active site through a secure hospital network. These electronic data collection forms include features such as sequential assignment of case numbers, error checking for incomplete and abnormal values, daily back-up, and monthly data transfer to the Coordinating Centre by a secure network after removal of patient identifiers.

For this analysis, descriptive statistics were computed for the frequency of specific CPN indicator conditions, maternal characteristics and past medical and surgical history, characteristics of the current pregnancy, and maternal and perinatal outcomes. The unit of analysis was the pregnancy. Missing data were identified for each outcome. Categorical data are presented as $\mathrm{n}(\%)$ and continuous data as mean (SD) or median (IQR), as appropriate. Chi-square tests were used to compare proportions, with a two-sided $P<$ 0.05 considered statistically significant.

\section{RESULTS}

Between August 1, 2005 and July 31, 2009, data from 2524 women (2536 pregnancies) in 14 active tertiary perinatal hospitals across Canada were submitted to the CPN. The details of women $(83.6 \%)$ and infants $(83.5 \%)$ followed 


\section{Cases entered into the CPN database and lost to follow-up before and after delivery}

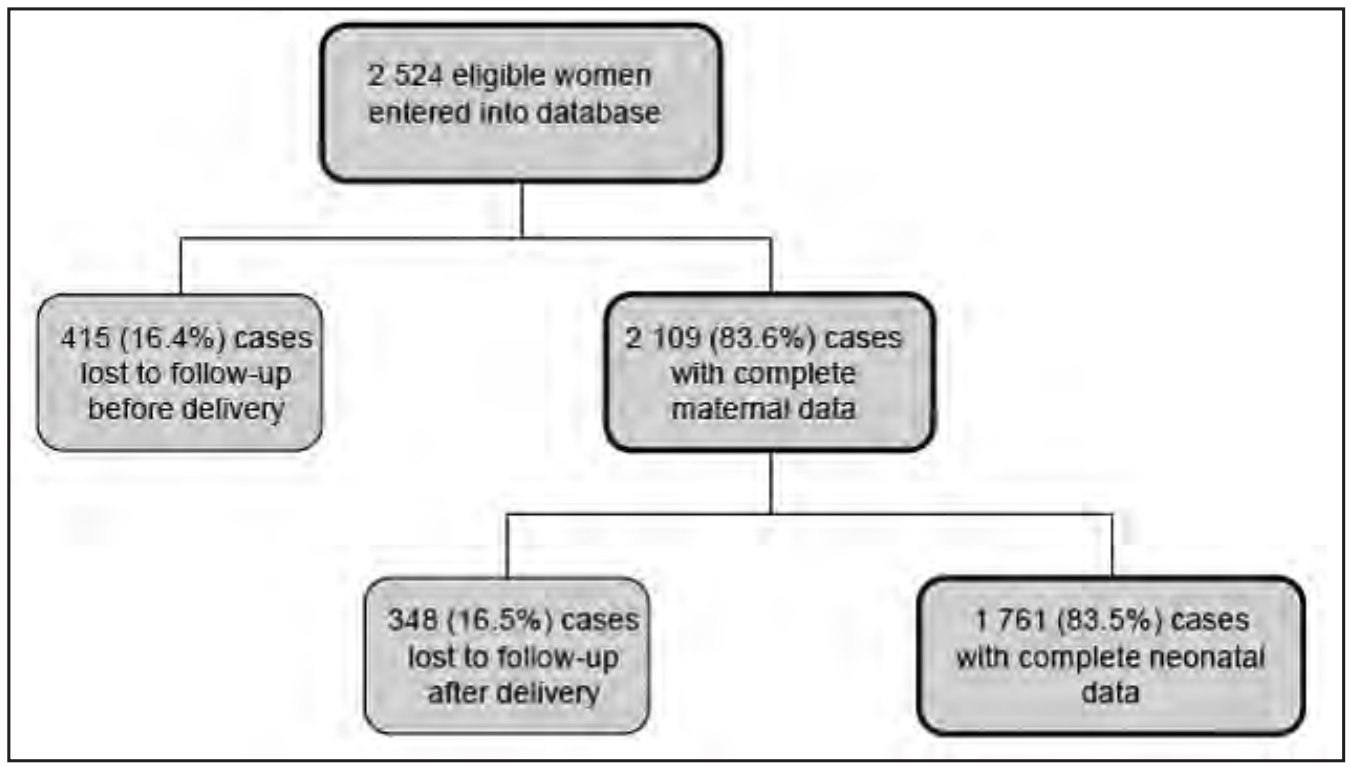

Table 1. Indicator conditions for the first 2524 women enrolled in the Canadian Perinatal Network

\begin{tabular}{|c|c|c|c|c|c|c|c|c|}
\hline \multirow[b]{2}{*}{$\begin{array}{l}\text { Indicator condition for } \\
\text { enrolment* }\end{array}$} & \multicolumn{2}{|c|}{ Total $(n=2524)$} & \multicolumn{2}{|c|}{$\begin{array}{l}\text { Women followed to delivery } \\
\qquad(\mathrm{n}=2109)\end{array}$} & \multicolumn{2}{|c|}{$\begin{array}{l}\text { Women lost to follow-up } \\
\qquad(n=415)\end{array}$} & \multicolumn{2}{|c|}{$\begin{array}{l}P \text { (followed up vs. } \\
\text { lost to follow-up) }\end{array}$} \\
\hline & $\begin{array}{l}\text { Women } \\
\mathrm{n}(\%) \dagger\end{array}$ & $\begin{array}{c}\text { Condition } \\
\text { severe, n (\%) }\end{array}$ & $\begin{array}{l}\text { Women } \\
\mathrm{n}(\%) \dagger\end{array}$ & $\begin{array}{c}\text { Condition } \\
\text { severe, } \\
\mathrm{n}(\%)^{*}\end{array}$ & $\begin{array}{l}\text { Women } \\
\mathrm{n}(\%) \dagger\end{array}$ & $\begin{array}{c}\text { Condition } \\
\text { severe, n (\%) }\end{array}$ & Women $†$ & $\begin{array}{c}\text { Condition } \\
\text { severe }\end{array}$ \\
\hline PTL with contractions & $692(27.4)$ & $273(39.5)$ & $570(27.0)$ & $260(45.6)$ & $122(29.4)$ & $13(10.7)$ & 0.34 & $<0.001$ \\
\hline $\mathrm{APH}$ & $659(26.1)$ & $57(8.7)$ & $540(25.6)$ & $51(9.4)$ & $119(28.7)$ & $6(5.0)$ & 0.20 & 0.15 \\
\hline PPROM & $580(23.0)$ & $72(12.4)$ & $516(24.5)$ & $65(12.6)$ & $64(15.4)$ & $7(10.9)$ & $<0.001$ & 0.84 \\
\hline Short cervix (no contractions) & $412(16.3)$ & $153(37.1)$ & $321(15.2)$ & $127(39.6)$ & $91(21.9)$ & $26(28.6)$ & 0.001 & 0.07 \\
\hline Gestational hypertension & $276(10.9)$ & $197(71.4)$ & $262(12.4)$ & $192(73.3)$ & $14(3.4)$ & $5(35.7)$ & $<0.001$ & 0.005 \\
\hline Prolapsing membranes & $236(9.4)$ & $155(65.7)$ & $206(9.8)$ & $143(69.4)$ & $30(7.2)$ & $12(40.0)$ & 0.12 & 0.003 \\
\hline Idiopathic IUGR & $146(5.8)$ & $90(61.6)$ & $128(6.1)$ & $78(60.9)$ & $18(4.3)$ & $12(66.7)$ & 0.21 & 0.80 \\
\hline
\end{tabular}

${ }^{*}$ Definitions of the indicator conditions for enrolment in CPN are provided in Appendix 1.

$\dagger$ The indicator conditions are not mutually exclusive.

up from enrolment to final hospital discharge are shown in the Figure. The "indicator" conditions at enrolment in the CPN are shown in Table 1 . Overall, $76.5 \%$ of women had either PTL with contractions, APH, or PPROM. Six hundred fourteen women $(24.3 \%)$ had more than one indicator condition at enrolment, usually PTL with either $\operatorname{PPROM}(4.8 \%)$ or APH $(3.5 \%)$. Women who were followed to delivery more often had severe PTL, PPROM, severe gestational hypertension, or severe prolapsing membranes (see Appendix 1 for definitions regarding severity). Women who were lost to follow-up before delivery were more likely to have a short cervix without contractions.

The maternal characteristics and pregnancy history of the women enrolled in the database are shown in Table 2 . The average maternal age was 30.6 years and approximately one half were parous. A substantial amount of information related to ethnicity, BMI, and prenatal care was missing; among those with information on these determinants, most were Caucasian (67\%), had a normal BMI, and had had four or more prenatal care visits. A minority of women $(<5 \%)$ had a pre-existing medical condition, including diabetes or hypertension. Among parous women, previous Caesarean section $(27.3 \%)$ and previous preterm birth at $<37$ weeks $(32.4 \%)$ or $<34$ weeks $(20.6 \%)$ were common antecedents. Most women did not smoke or use alcohol or illicit drugs during pregnancy. Women were enrolled in the CPN at a mean gestational age of 25.9 (SD 1.9) weeks and a median gestational age of 26.1 (IQR 24.3 to 27.6) weeks. Women who were followed to delivery were slightly 
Table 2. Maternal characteristics and pregnancy history of the initial 2524 women enrolled in the Canadian Perinatal Network

\begin{tabular}{|c|c|c|c|c|}
\hline & Total N = 2524 & Women followed to delivery $(n=2109)$ & Women lost to follow-up $(n=415)$ & $P$ \\
\hline Maternal age at EDD, year & $30.6 \pm 5.9$ & $30.71 \pm 6.0$ & $29.94 \pm 5.5$ & 0.02 \\
\hline Ethnicity, n (\%) & & & & 0.60 \\
\hline Caucasian & $1148(67.0)$ & $960(66.3)$ & $188(70.4)$ & \\
\hline Asian or Indo-Canadian & $296(17.3)$ & $251(17.4)$ & $45(16.9)$ & \\
\hline Afro-Canadian & $109(6.4)$ & $97(6.7)$ & $12(4.5)$ & \\
\hline Native Canadian & $89(5.2)$ & $77(5.3)$ & $12(4.5)$ & \\
\hline Other & $72(4.2)$ & $62(4.3)$ & $10(3.8)$ & \\
\hline Missing, $\mathrm{n}(\%)^{*}$ & $810(32.1)$ & $662(31.4)$ & $148(35.7)$ & \\
\hline Socioeconomic status (income, $\$$ ) $†$ & $67079 \pm 15978$ & $67230 \pm 16130$ & $66293 \pm 15158$ & 0.37 \\
\hline Missing & $78(3.1)$ & $58(2.8)$ & $20(4.8)$ & \\
\hline Pre-pregnancy BMI (kg/m²), n (\%) & & & & 0.04 \\
\hline Underweight (BMI < 20) & $257(18.7)$ & $209(18.0)$ & $48(21.9)$ & 0.19 \\
\hline Normal weight (BMI 20-24) & $571(41.4)$ & $469(40.5)$ & $102(46.8)$ & 0.10 \\
\hline Overweight (BMI 25-29) & $293(21.3)$ & $259(22.4)$ & $34(15.5)$ & 0.02 \\
\hline Obese $(\mathrm{BMI} \geq 30)$ & $257(18.7)$ & $222(19.2)$ & $35(16.0)$ & 0.30 \\
\hline Missing & $1146(45.4)$ & $950(45.1)$ & $196(47.2)$ & \\
\hline \multicolumn{5}{|l|}{ Pre-existing medical conditions, n (\%) } \\
\hline Pre-existing hypertension & $106(4.2)$ & $96(4.5)$ & $10(2.4)$ & 0.05 \\
\hline Diabetes mellitus & $44(1.7)$ & $36(1.7)$ & $8(1.9)$ & 0.69 \\
\hline Venous thromboembolism & $14(0.60)$ & $12(0.6)$ & $2(0.5)$ & $>0.99$ \\
\hline Uterine structural abnormalities $\ddagger$ & $98(3.9)$ & $87(4.1)$ & $11(2.7)$ & 0.17 \\
\hline Other§ & $87(3.5)$ & $76(3.6)$ & $11(2.7)$ & 0.38 \\
\hline Multiple pregnancy, n (\%) & $395(15.7)$ & $391(18.5)$ & $4(1.0)$ & $<0.001$ \\
\hline \multicolumn{5}{|l|}{ Parity, n (\%) } \\
\hline Nulliparity & $1240(49.1)$ & $1,054(50.0)$ & $186(44.8)$ & 0.06 \\
\hline Parity of 1 & $732(29.0)$ & $608(28.8)$ & $124(29.88)$ & 0.68 \\
\hline Parity $\geq 2$ & $552(21.9)$ & $447(21.2)$ & $105(25.3)$ & 0.07 \\
\hline Parous women & $n=1284$ & $\mathrm{n}=1055$ & $n=229$ & \\
\hline Previous Caesarean section, n (\%) & $351(27.3)$ & $294(27.9)$ & $57(24.9)$ & 0.41 \\
\hline \multicolumn{5}{|l|}{ Previous preterm birth, n (\%) } \\
\hline$<37$ weeks & $416(32.4)$ & $342(32.4)$ & $74(32.3)$ & $>0.99$ \\
\hline$<34$ weeks & $265(20.6)$ & $215(20.4)$ & $50(21.8)$ & 0.65 \\
\hline Smoking during pregnancy, n (\%) & $445(17.8)$ & $365(17.5)$ & $80(19.6)$ & 0.32 \\
\hline Missing & $25(1.0)$ & $18(0.9)$ & $7(1.7)$ & \\
\hline Alcohol use during pregnancy, n (\%) & $119(4.8)$ & $51(2.4)$ & $5(1.2)$ & 0.20 \\
\hline Missing & $31(1.2)$ & $20(1.0)$ & $11(2.7)$ & \\
\hline Illicit drug use during pregnancy, n (\%) & $83(3.3)$ & $73(3.5)$ & $10(2.5)$ & 0.36 \\
\hline Missing & $28(1.11)$ & $18(0.85)$ & $10(2.41)$ & \\
\hline \multicolumn{5}{|l|}{ Prenatal care, n (\%) } \\
\hline$\leq 4$ visits & $461(26.85)$ & $457(27.04)$ & $4(14.81)$ & 0.19 \\
\hline$>4$ visits & $1213(70.65)$ & $1194(70.65)$ & $19(70.37)$ & $>0.99$ \\
\hline Missing & $807(31.97)$ & $419(19.87)$ & $388(93.49)$ & \\
\hline \multicolumn{5}{|l|}{ Gestational age at enrolment, week } \\
\hline Mean (SD) & $25.9 \pm 1.9$ & $25.9 \pm 1.93$ & $26.1 \pm 1.8$ & 0.05 \\
\hline Median (IQR) & $26.1(24.3-27.6)$ & $26.1(24.3-27.6)$ & $26.3(24.7-27.6)$ & \\
\hline
\end{tabular}

EDD: estimated date of delivery.

*Missing data are indicated for each applicable variable. If no missing data are indicated, there were none.

†Expressed as median neighbourhood income levels, derived from postal codes and census enumerator data obtained from Statistics Canada.

†Uterine structural abnormalities includes bicornuate uterus (40), didelphic uterus (4), leiomyomas (37), unicornuate uterus (5), and other (14).

§Includes thrombophilia (30), hepatitis B (13), hepatitis C (13), HIV (2), and genital herpes (33) 


\section{Table 3. General pregnancy and maternal outcomes for women followed to delivery in the Canadian Perinatal Network}

\begin{tabular}{|c|c|}
\hline & Total $n=2109$ \\
\hline Gestational age at delivery, week, Mean (SD) & $29.9(5.1)$ \\
\hline Median (IQR) & $28.4(26.1-33.6)$ \\
\hline Birth at $\geq 37$ weeks, n (\%) & $304(14.3)$ \\
\hline \multicolumn{2}{|l|}{ Preterm birth, weeks, n (\%) } \\
\hline$<37$ & $1798(85.3)$ \\
\hline$<34$ & $1591(75.4)$ \\
\hline$<29$ & $1197(56.8)$ \\
\hline \multicolumn{2}{|l|}{ Maternal outcomes, n (\%) } \\
\hline Missing* & $1(0.05)$ \\
\hline Admission per woman & $1(1,2)$ \\
\hline $\begin{array}{l}\text { Gestational hypertension developed after } \\
\text { enrolment, } \mathrm{n}(\%)\end{array}$ & $150(7.1)$ \\
\hline $\begin{array}{l}\text { Placental abruption developed after } \\
\text { enrolment, } \mathrm{n}(\%)\end{array}$ & $88(4.2)$ \\
\hline $\begin{array}{l}\text { One or more serious maternal } \\
\text { complications, } \mathrm{n}(\%)\end{array}$ & $562(26.7)$ \\
\hline Death & $1(0.05)$ \\
\hline Receipt of blood products & $86(4.1)$ \\
\hline Admission to intensive care unit $†$ & $67(3.2)$ \\
\hline Chorioamnionitis & $405(19.6)$ \\
\hline Sepsis/endometritis & $24(1.1)$ \\
\hline Other $\ddagger$ & $72(3.4)$ \\
\hline
\end{tabular}

*Missing data are indicated for each applicable variable. If no missing data are indicated, then there were none.

†Intensive care refers to a full-service adult intensive care unit, and not an intermediate-care adult area of the hospital (e.g., "high dependency unit").

†Other complications included central nervous system: eclampsia (5), stroke (1), neurological event (1); respiratory: intubation (6), non-invasive ventilation (4), pulmonary edema (21), oxygen requirement (7); cardiovascular: use of three parenteral antihypertensives (7), positive inotropic support (1), myocardial ischemia/infarction (1); hematological: hysterectomy (10), uterine artery embolization (2), thromboembolism(6); hepatic/gastrointestinal: hepatic failure (10); renal: acute renal failure (5); other (16).

older, were enrolled at a slightly earlier gestational age, were more likely to have a multiple pregnancy, and were more likely to have been overweight pre-pregnancy. The median latency (pregnancy prolongation from enrolment) was 10 days (IQR 2 to 51).

Pregnancy and maternal outcomes are shown in Table 3. The median gestational age at delivery was 28.4 weeks. After a median of one admission, $57.0 \%$ of women delivered at $<29$ weeks, $75.8 \%$ at $<34$ weeks, and $85.7 \%$ at $<37$ weeks. A minority of women developed gestational hypertension $(7.1 \%)$ or APH (4.2\%) following admission. There was one maternal death after a late presentation with PPROM and sepsis; this patient delivered on the day of hospital admission, and, despite treatment with broad spectrum antibiotics, she was admitted to the ICU on the following day. The baby spent 81 days in the NICU and suffered multiple complications, including retinopathy of prematurity and hypoxic-ischemic encephalopathy. One or more serious maternal complications occurred in 562 $(26.7 \%)$ women. The most common of these complications was chorioamnionitis $(\mathrm{n}=405), 53.9 \%$ of which occurred among women with PPROM.

The perinatal outcomes are shown in Table 4. Infant data were available for 1761 women $(83.5 \%)$ with 2086 babies. The pregnancy outcomes of stillbirth $(8.2 \%)$ and neonatal death $(16.3 \%)$ were associated with a congenital anomaly in $13 / 145(9.0 \%)$ and $43 / 263(16.4 \%)$ cases, respectively. Of the 239 pregnancies (329 babies) with a congenital anomaly, $79.9 \%$ were considered major. Most babies were appropriately grown for gestational age. Admission to NICU occurred for the babies of $60.7 \%$ of pregnancies, and of these $223 / 1069$ (20.9\%) had a congenital anomaly. Most babies admitted to NICU stayed for at least one week. Serious neonatal morbidities occurred in 566 (35.0\%) of live births.

\section{DISCUSSION}

From August 2005 to July 2009, the CPN assembled information on a cohort of 2524 women with threatened preterm delivery at $22+0$ to $28+6$ weeks. The conditions responsible for threatened very preterm delivery included PTL with contractions (27.4\%), short cervix without contractions (16.3\%), prolapsing membranes (9.4\%), PPROM (23.0\%), APH (26.1\%), gestational hypertension $(10.9 \%)$, and IUGR (5.8\%). Approximately one half of these women delivered before 29 weeks, with another $25 \%$ delivering at 29 to $33+6$ weeks, and $15 \%$ delivering at $34+0$ to $36+6$ weeks. Not surprisingly, the incidence of perinatal complications in this cohort was high. The mean gestational age at delivery was $29.9 \pm 5.1$ weeks with an associated perinatal mortality of $24.5 \%$. Admission to NICU was required for $60.7 \%$ of babies, $96.3 \%$ of whom stayed for at least one week and $35.0 \%$ of whom had one or more serious neonatal complications. More than one quarter of enrolled women $(26.7 \%)$ suffered one or more serious maternal complications, usually chorioamnionitis. There was one maternal death from sepsis.

The primary strength of the CPN is its national scope and the size of the cohort assembled.

As the $\mathrm{CPN}$ is a national network recruiting across Canada using continuous quality improvement methodology, concerns about generalizability are limited. Women with 
threatened very preterm birth at $<29$ weeks usually present at, or are transferred to, a tertiary perinatal unit. Using this information, Canadian tertiary centres will now be able to benchmark their performance against that of their Canadian peers, an exercise that has proved to be valuable in international pregnancy hypertension benchmarking.,

Misclassification arising from data abstraction is unlikely, as we implemented abstractor training, used standard codebooks, and randomly re-abstracted charts for checking. Admission bias was minimized by Canada's public health care system, in which all women at risk of delivering $<29$ weeks' gestation are admitted to tertiary level units prior to delivery. The numbers of women available for studies of specific conditions varied considerably, and small numbers may preclude meaningful analysis of some issues. However, enrolment in CPN is ongoing and we anticipate a substantial increase in cohort size.

An additional important strength of the $\mathrm{CPN}$ is our linkage with the successful national Canadian Neonatal Network ${ }^{8}$ and the new Canadian Neonatal Follow-up Network, which will track infants born at $<29$ weeks up to 36 months of age, as part of the MiCare Network. Since 2005, the CNN has generated important information necessary for making improvements in NICU management. ${ }^{8-10}$ Preliminary analysis of maternal information in the $\mathrm{CNN}$ has suggested that, for pregnancies complicated by hypertension, betweencentre variations in obstetric practice were associated with variations in neonatal survival, after correction for NICU practice and antenatal corticosteroid use. ${ }^{11}$ Further analyses will help identify the practices associated with improved maternal and neonatal outcomes.

The major limitation to this study was loss to followup. Maternal loss to follow-up before delivery was approximately $20 \%$. Although there was no a priori reason to suspect systematic reasons for the losses to followup, women who have been followed up appear to be at a higher risk of very preterm birth. The primary cause of missing data has been the quality of antenatal records (with information missing on specific determinants such as pre-pregnancy weight) and, for women lost to follow-up, subsequent delivery closer to home and outside a tertiary perinatal unit. For neonatal outcomes, missing data arose because $\mathrm{CNN}$ data are updated centrally on an annual basis, and a reduction in missing information is anticipated once the year-end process is completed. An additional strength of the CPN is that information is captured for stillbirths and infants who die either before admission to the NICU or within 24 hours of admission. There are several existing regional or provincial reproductive care programs

\begin{tabular}{|c|c|}
\hline $\begin{array}{l}\text { Women followed to delivery with infant } \\
\text { outcomes }\end{array}$ & $\mathrm{n}=1761$ \\
\hline \multirow[t]{2}{*}{ Infants } & $n=2086$ \\
\hline & $\mathrm{n}(\%)$ \\
\hline \multicolumn{2}{|l|}{ Perinatal mortality } \\
\hline Stillbirth & $145 / 1761(8.2)$ \\
\hline Neonatal death & $263 / 1616$ (16.3) \\
\hline Congenital anomalies & $239 / 1759(13.6)$ \\
\hline Missing & 2/1761 (0.1) \\
\hline \multicolumn{2}{|l|}{ SGA infant } \\
\hline$<10$ th centile & $278 / 1719(16.2)$ \\
\hline$<3$ rd centile & $108 / 1719(6.3)$ \\
\hline Missing & $42 / 1761(2.4)$ \\
\hline NICU admission & $1069 / 1761(60.7)$ \\
\hline Stay $\geq 24 \mathrm{hr}$ & $1062 / 1069$ (99.4) \\
\hline Stay $\geq 48 \mathrm{hr}$ & $1041 / 1069(97.4)$ \\
\hline Stay $\geq 7 \mathrm{~d}$ & $1029 / 1069$ (96.3) \\
\hline Serious neonatal morbidities* & $566 / 1616(35.0)$ \\
\hline Bronchopulmonary dysplasia* & $334 / 1390(24.03)$ \\
\hline Missing & $134 / 1616(8.29)$ \\
\hline Retinopathy of prematurity* & $62 / 1128(5.5)$ \\
\hline Missing & $330 / 1616(20.42)$ \\
\hline Severe brain injury* & $117 / 1417(8.26)$ \\
\hline Missing & 199/1616 (12.31) \\
\hline Necrotizing enterocolitis & $91 / 1606(5.67)$ \\
\hline Missing & $10 / 1616(0.62)$ \\
\hline Sepsis & $239 / 1614(14.81)$ \\
\hline Missing & $2 / 1616(0.12)$ \\
\hline Hypoxic-ischemic encephalopathy* & $0 / 638(0)$ \\
\hline Missing & $7 / 1616(0.43)$ \\
\hline
\end{tabular}

*Denominator reflects the number of babies for which this outcome is relevant. Please see Appendix 1 for the definition of each specific morbidity. The denominator for one or more serious neonatal morbidities was live births. 
that have perinatal surveillance databases. ${ }^{4}$ However, collectively, these programs do not cover the country and most focus their data collection on demographics, past obstetrical history, maternal lifestyle (e.g., smoking), labour and delivery, and basic neonatal outcomes, with little information about interventions. ${ }^{4}$ For example, only two programs collect specific information about magnesium sulphate use, although this is the ideal therapy and an auditable standard for the management of women with severe preeclampsia or eclampsia. This difference in focus between the existing population-based perinatal database and the CPN database also highlights another facet of the processes required for monitoring maternal health. Whereas population-based perinatal databases may be ideal for identifying temporal or regional disparities in maternal health, detailed investigation of identified disparities may require information on interventions and processes of care that the CPN collects. For example, although postpartum hemorrhage was recognized to be increasing in Canada in $2003,{ }^{12,13}$ the reasons for the increase have yet to be elucidated.

In conclusion, the Canadian Perinatal Network has successfully created an infrastructure for collecting information related to threatened very preterm birth from tertiary perinatal hospitals in Canada. The data collected will enable an examination of obstetric practice, and practices associated with good outcomes can be identified, widely implemented, and audited through the CPN. The CPN will be able to address issues as diverse as the role of bed rest as an intervention for high risk pregnancies and specific antibiotic regimens used in the management of PPROM. ${ }^{14}$ The CPN dataset is open to CPN investigators and clinicians or investigators who are working with a CPN Collaborator ${ }^{15}$ and who are interested in condition-specific analyses relating processes of care to maternal or perinatal outcomes.

\section{ACKNOWLEDGEMENTS}

The authors are grateful to the CPN Site Coordinators and previous CPN National Co-ordinators (D. Chaplain, T. Morris, and M. Fazio). We would like to acknowledge funding support from the Canadian Institutes of Health Research and from the Ontario Ministry of Health and Long-term Care for their support of the MiCare Coordinating Centre at Mount Sinai Hospital, Toronto, ON.

\section{REFERENCES}

1. Health Canada. Special report on maternal mortality and severe morbidity in Canada—enhanced surveillance: the path to prevention. Ottawa: Minister of Public Works and Government Services Canada;2004.

2. Bolan JC. Thromboembolic complications of pregnancy. Clin Obstet Gynecol 1983;26:913-22.

3. Smith G, Rafuse C, Anand N, Brennan B, Connors G, Crane J, et al. Prevalence, management, and outcomes of preterm prelabour rupture of the membranes of women in Canada. J Obstet Gynaecol Can 2005;27:547-53.

4. Massey KA, Magee LA, Dale S, Claydon J, Morris TJ, von Dadelszen P, et al. A current landscape of provincial perinatal data collection in Canada. J Obstet Gynaecol Can 2009;31:236-46.

5. Ezzat H, Magee LA, Ross S, von Dadelszen P, Morris TJ, Liston RM. Protecting patients or a barrier to research? Examining the role of Canadian research ethics boards. BMC Health Serv Res 2010;10:223.

6. Thornton C, Hennessy A, von Dadelszen P, Nishi C, Makris A, Ogle R. An international benchmarking collaboration: measuring outcomes for the hypertensive disorders of pregnancy. J Obstet Gynaecol Can 2007;29:794-800.

7. Thornton CE, von Dadelszen P, Makris A, Tooher JM, Ogle RF, Hennessy A. Acute pulmonary oedema as a complication of hypertension during pregnancy. Hypertens Pregnancy 2009 Nov 10.[Epub ahead of print]

8. Lee SK, McMillan DD, Ohlsson A, Pendray M, Synnes A, Whyte R, et al. Variations in practice and outcomes in the Canadian NICU network: 19961997. Pediatrics 2000;106:1070-9.

9. Synnes AR, Chien LY, Peliowski A, Baboolal R, Lee SK. Variations in intraventricular hemorrhage incidence rates among Canadian neonatal intensive care units. J Pediatr 2001;138:525-31.

10. Lee SK, Normand C, McMillan D, Ohlsson A, Vincer M, Lyons C. Evidence for changing guidelines for routine screening for retinopathy of prematurity. Arch Pediatr Adolesc Med 2001;155:387-95.

11. Hayter MA, Anderson L, Claydon J, Magee LA, Little R, Liston RM, et al. Variations in early and intermediate neonatal outcomes for inborn infants admitted to a Canadian NICU and born of hypertensive pregnancies. J Obstet Gynaecol Can 2005;27:25-32.

12. Health Canada. Canadian Perinatal Health Report. Ottawa: Minister of Public Works and Government Services Canada;2003.

13. Joseph KS, Rouleau J, Kramer MS, Young DC, Liston RM, Baskett TF; Maternal Health Study Group of the Canadian Perinatal Surveillance System. Investigation of an increase in postpartum haemorrhage in Canada. BJOG 2007;114:751-9.

14. Yudin MH, van Schalkwyk J, Van Eyk N, Boucher M, Castillo E, Cormier B, et al. Antibiotic therapy in preterm premature rupture of the membranes. J Obstet Gynaecol Can 2009;31:863-74.

15. Canadian Perinatal Network. List of participating institutions and members. Available at:http://www.cpn-rpc.org/members.asp. Accessed December 22, 2010. 


\section{Appendix 1. Canadian Perinatal Network definitions (May 2008 manual; www.cpn-rpc.org)}

\begin{tabular}{lll}
\hline Indicators/ Outcomes & Definitions & "Severe" definition \\
\hline Preterm labour with contractions & $\begin{array}{l}\text { Regular contractions every } 5 \text { minutes or more frequently, with } \\
\text { documented cervical change. Gestational age on the date of } \\
\text { condition onset must be less than } 37+0 \text { weeks. }\end{array}$ & $\begin{array}{l}\text { Regular contractions, with cervix } \\
<0.5 \mathrm{~cm} \text { in length and } \geq 2 \mathrm{~cm} \text { dilated. }\end{array}$
\end{tabular}

Short cervix without contractions Incompetent cervix or cervical shortening (to less than $2.0 \mathrm{~cm}$; by endovaginal ultrasound examination) without regular contractions (i.e., occurring every 5 minutes or more frequently).

Prolapsing membranes without contractions

PPROM

Idiopathic IUGR

Gestational hypertension

$\mathrm{APH}$
Dilated cervix or prolapsing membranes at or beyond the external os as visualized on speculum examination, or any cervical dilatation of external os by endovaginal ultrasound examination, without regular contractions (i.e., occurring every 5 minutes or more frequently).

Prelabour rupture of membranes confirmed by positive ferning and/or pooling of amniotic fluid. Prelabour means prior to onset of regular contractions (i.e., occurring every 5 minutes or more frequently). Gestational age on the date of condition onset must be less than $37+0$ weeks.

Ultrasonographically determined abdominal circumference less than the 10th percentile by local definitions (e.g., provincial data, Jeanty chart), without a recognized cause other than gestational hypertension. Cases with recognized chromosomal abnormality, twin-to-twin transfusion, etc. were not eligible. For multiples, only one fetus must have IUGR.

Systolic blood pressure (SBP) $\geq 140 \mathrm{mmHg}$ or diastolic blood pressure (DBP) $\geq 90 \mathrm{mmHg}$, twice, at least 4 hours apart, developing after 20 weeks' gestation.
Short cervix without regular contractions: by endovaginal ultrasound, cervical length $<1.0 \mathrm{~cm}$.

Dilated cervix $\geq 2 \mathrm{~cm}$ or "hour-glassing" (i.e., membranes beyond external cervical os).

PPROM prior to 22 weeks.

Abdominal circumference $(A C)$ $<3$ rd centile.

Gestational hypertension with proteinuria and one or more adverse conditions:

- maternal signs: BP of $170 / 110 \mathrm{mmHg}$ or more, platelets $<100000$, urine output $<500 \mathrm{~mL} / \mathrm{d}$, pulmonary edema, elevated liver enzymes (AST or ALT $\geq 70 \mathrm{IU} / \mathrm{L}$ )

- maternal symptoms: severe nausea and vomiting, frontal headache, visual disturbances, persistent abdominal pain in right upper quadrant, chest pain or shortness of breath, suspected placental abruption, HELLP syndrome (HELLP is defined as LDH $\geq 600 \mathrm{IU} / \mathrm{L}$, AST or ALT $\geq 70 \mathrm{IU} / \mathrm{L}$ and platelets $<150 \times 106 /$ L)

- fetal signs: intrauterine growth restriction $(<10$ th centile by local criteria), oligohydramnios, or absent/ reversed umbilical artery end diastolic flow by Doppler velocimetry

Requiring transfusion of any blood product, within 6 hours of admission, antenatally or postnatally.
Greater than $15 \mathrm{~mL}$ of vaginal bleeding prior to the onset of labour $15 \mathrm{~mL}$ of blood was considered to be equivalent to a blood spot of approximately $2.5 \mathrm{~cm}$ in diameter (a Loonie coin). The bleeding did not have to occur all at once. 


\section{Appendix 1. Continued. Canadian Perinatal Network definitions (May 2008 manual; www.cpn-rpc.org)}

Indicators/ Outcomes $\quad$ Definitions "Severe" definition

Serious maternal complications Maternal death, or major organ system dysfunction (e.g., stroke), transfusion of at least one blood product during admission, or admission to adult intensive care unit or highdependency obstetrical unit, or diagnosis of suspected or confirmed chorioamnionitis

Gestational age at delivery

Neonatal death

Birth weight

Broncho-pulmonary dysplasia

Retinopathy of prematurity

Severe brain injury

Necrotizing enterocolitis

Sepsis

Hypoxic-ischemic encephalopathy
Age in weeks from the best estimate of last menstrual period (LMP) to the neonate's date of birth (DOB); calculation based on LMP, estimated date of delivery (EDD), and actual DOB

Death within the first 28 days of life or prior to discharge home.

Weight in grams as recorded by the birth hospital or weight/best estimate within the first 24 hours of life when unavailable at birth.

Supplemental oxygen required at 36 weeks corrected post-gestational age in babies born at $\leq 32$ weeks' gestational age.

Stage 3,4 , or 5 in one or both eyes (examined if birthweight is $<1500 \mathrm{~g}$ or gestational age at birth is $<32$ weeks).

Intraventricular hemorrhage grade III or IV, ventricular enlargement with or without germinal matrix or intraventricular hemorrhage, parenchymal echodensities, lucencies in the white or grey matter, periventricular leukomalacia, evidence of diffuse brain lesions in the white matter, or multiple cysts in the white matter on ultrasound.

Pneumatosis intestinalis (air in the bowel wall or portal/ hepatic air), diagnosed by X-ray, at surgery, or at autopsy.

One or more positive cultures of blood or cerebrospinal fluid.

Ischemic encephalopathy according to the definition of Sarnat (stages 2 and 3). This diagnosis was applied only to infants $>2000 \mathrm{~g}$ or $\geq 35$ weeks gestational age at birth with both history of a perinatal event consistent with injury (e.g., fetal distress, low Apgar, or need for resuscitation) and an abnormal neurological examination over the first 2 to 3 days of life. Alternatively, the diagnosis could be made from the neonatal intensive care discharge summary if it indicated one of the following: hypoxic-ischemic encephalopathy, ischemic encephalopathy, asphyxia, birth asphyxia, or perinatal asphyxia.

\begin{tabular}{ll}
\hline \multicolumn{2}{c}{ Appendix 2. Additional Canadian Perinatal Network Members } \\
\hline Member & Centre \\
C Burym & St. Boniface General Hospital \& Winnipeg Health Science Centre, Winnipeg MB \\
G Carson & Regina General Hospital, Regina SK \\
J Dansereau & Royal Victoria Hospital, Victoria BC \\
R Gratton & St. Joseph's Health Centre, London ON \\
S McDonald & McMaster University Health Centre, Hamilton ON \\
F Olatunbosun & Royal University Hospital, Saskatoon SK \\
J-P Pasquier & Université de Sherbrooke, Sherbrooke QC \\
\hline
\end{tabular}

